\title{
Accuracy of the discharge destination field in administrative data for identifying transfer to a long-term acute care hospital
}

\author{
Jeremy M Kahn ${ }^{1 *}$, Theodore J Iwashyna²
}

\begin{abstract}
Background: Long-term acute care hospitals (LTACS) provide specialized care for patients recovering from severe acute illness. In order to facilitate research into LTAC utilization and outcomes, we studied whether or not the discharge destination field in administrative data accurately identifies patients transferred to an LTAC following acute care hospitalization.

Findings: We used the 2006 hospitalization claims for United States Medicare beneficiaries to examine the performance characteristics of the discharge destination field in the administrative record, compared to the reference standard of directly observing LTAC transfers in the claims. We found that the discharge destination field was highly specific $(99.7 \%, 95$ percent Cl: $99.7 \%$ - 99.8\%) but modestly sensitive $(77.3 \%$, 95 percent Cl: $77.0 \%$ 77.6\%), with corresponding low positive predictive value (72.6\%, 95 percent $\mathrm{Cl}: 72.3 \%-72.9 \%)$ and high negative predictive value (99.8\%, 95 percent Cl: $99.8 \%$ - 99.8\%). Sensitivity and specificity were similar when limiting the analysis to only intensive care unit patients and mechanically ventilated patients, two groups with higher rates of LTAC utilization. Performance characteristics were slightly better when limiting the analysis to Pennsylvania, a state with relatively high LTAC penetration.

Conclusions: The discharge destination field in administrative data can result in misclassification when used to identify patients transferred to long-term acute care hospitals. Directly observing transfers in the claims is the preferable method, although this approach is only feasible in identified data.
\end{abstract}

\section{Objective}

Long-term acute care (LTAC) hospitals specialize in the care of severely ill hospitalized patients with longer than average lengths of stay [1]. Typically LTACs provide care for patients with complex care needs after an episode of severe acute illness, such as patients requiring intensive wound care or prolonged mechanical ventilation [2]. LTACs are among the fastest growing segments of the US health care system, increasing at an average rate of approximately $10 \%$ per year [3]. Despite such growth, it is not clear whether or not LTACs provide value over the alternatives sites of care such as skilled nursing facilities, rehabilitation hospitals, or intermediate care units within acute care hospitals [4]. Research is

\footnotetext{
* Correspondence: jmkahn@mail.med.upenn.edu

'Center for Clinical Epidemiology \& Biostatistics, University of Pennsylvania School of Medicine, Blockley Hall 723, 423 Guardian Drive, Philadelphia, PA
} 19104

(c) 2010 Kahn et al; licensee BioMed Central Ltd. This is an Open Access article distributed under the terms of the Creative Commons Attribution License (http://creativecommons.org/licenses/by/2.0), which permits unrestricted use, distribution, and reproduction in any medium, provided the original work is properly cited. needed to examine the factors related to LTAC utilization and the outcomes of patients transferred to LTACs. Large, multi-center administrative datasets are an important resource for research on the organization of care [5]. Yet administrative data frequently do not contain direct patient identifiers, making it impossible to identify transfers to LTACs. An alternate approach is to use the "discharge destination" field, which is commonly available in administrative data and usually contains an LTAC-specific code. However, administrative data often contain coding errors [6], and whether or not the discharge destination field accurately identifies transfer to an LTAC is unknown. Prior to using the discharge destination field to perform LTAC-related research, it is important to better understand its performance compared to more direct methods of identifying transfers. The objective of this study was to determine the accuracy of the discharge destination field in administrative 
data, compared to the reference standard of directly observing such transfers in the data.

\section{Methods}

We performed a cohort study to determine the accuracy of the discharge destination field administrative data for identifying patients transferred to an LTAC after an acute care hospitalization. We used the 2006 United States Medicare Provider Analysis and Review (MedPAR) file, which contains patient-level clinical and demographic data for all hospitalizations of fee-for-service Medicare beneficiaries in the United States. MedPAR is a unique data source for this project, since it includes not only a discharge destination field specifying the location of the patient after transfer ("DSTNTNCD") but also direct patient identifiers which allow tracking of specific individuals across multiple hospitalizations, including hospitalizations in an LTAC. Thus we were able to compare LTAC transfers as defined in the discharge destination field to the reference standard to directly observing LTAC transfers in the administrative record.

All hospitalizations in an adult general medical-surgical hospital during 2006 were eligible for the analysis. We excluded patients $<65$ years of age, which are not typical of the elderly Medicare population, and patients hospitalized in Alaska and Hawaii, which have limited access to LTACs because of their unique geography. We categorized the discharge destination field into six mutually exclusive categories: home, skilled nursing facility or rehabilitation hospital, another acute care hospital, an LTAC, deceased, and other or unknown. Discharge to an LTAC was based on code 63, "Discharge/ transferred to a long term care hospital"), which is present in Medicare claims since 2002.

Independent from the discharge location field, we determined whether or not the patient actually was transferred to an LTAC by directly observing such transfers in the claims. For this step, LTACs were identified using hospital characteristics from the 2006 Centers for Medicare and Medicaid Health Cost Reporting Information System (provider type = general long-term) and the provider characteristics embedded in the MedPAR hospital provider number (provider type $=$ general long-term). These data sources can both be used to identify long-term acute hospitals. For hospitals in which the two data sources did not agree (27 of 6,680, $0.4 \%$, we performed internet searches and placed telephone calls to confirm the hospital type. We defined LTAC transfers as temporally adjacent hospitals (i.e. discharge from the first hospital on date $\mathrm{n}$ and admission to the second hospital on date $n$ or $n+1$ ), in which the first hospitalization is in a short stay hospital and the second hospitalization is in an LTAC [7].
We then created $2 \times 2$ contingency tables to determine the sensitivity, specificity, positive predictive value and negative predicted value of the discharge destination field compared to the reference standard of directly observing the LTAC transfer. We calculated exact confidence intervals for each value using the binomial distribution. We performed the analysis in three groups of patients: all acute care hospitalizations, the subset of acute care hospitalizations involving an intensive care unit (ICU) admission [8], and the subset of ICU patients receiving mechanical ventilation [9]. The last two groups were examined because LTAC utilization is particularly high in these groups, and therefore the performance characteristics of the discharge codes might vary from the general population. Finally, we repeated all analyses in Pennsylvania, a US state with relatively high LTAC penetration. All analyses were performed in Stata 11.0 (College Station, Texas, US). The University of Pennsylvania Institutional Review Board approved this research.

\section{Results}

Table 1 shows a tabulation of the discharge destination field in MedPAR categorized by whether or not the patient was actually transferred to an LTAC as observed in the claims. Nationwide $0.8 \%$ of acute care hospitalizations ended in a transfer to an LTAC. A higher proportion of hospitalizations involving intensive care $(2.3 \%)$ and mechanical ventilation (8.3\%) ended in an LTAC transfer. Slightly higher transfer rates were observed in Pennsylvania. In general, LTAC transfers misclassified by the discharge destination field (i.e. the false negatives) were identified as being transferred to a skilled nursing facility, rehabilitation hospital or another acute care hospital (Table 1). For example, in the entire US sample, of 19,543 false negatives, 11,854 (60.7\%) were listed as discharged to a skilled nursing facility or rehabilitation hospital and 5,870 (30.0\%) were listed as discharged to another short-term hospital.

Compared to the reference standard of directly observing transfers in the claims, the discharge destination field was modestly sensitive but highly specific (Table 2). Across all patient categories in the United States sensitivity ranged from $77.3 \%$ to $77.7 \%$ and the specificity ranged from $98.4 \%$ to $99.7 \%$. The positive predictive value ranged from $72.6 \%$ to $81.6 \%$, and as expected was higher in the higher prevalence groups. Due to the relatively low prevalence, negative predictive value approached $100 \%$. Compared to hospitalizations in the US as a whole, in Pennsylvania the sensitivity was slightly higher with similar specificity.

\section{Discussion}

We found that the discharge destination field in administrative data was only modestly accurate in identifying 
Table 1 Contents of the discharge destination field in Medicare categorized by actual transfer to a long-term acute care hospital

\begin{tabular}{|c|c|c|}
\hline & $\begin{array}{c}\text { Transferred to } \\
\text { LTAC }\end{array}$ & $\begin{array}{c}\text { Not transferred to } \\
\text { LTAC }\end{array}$ \\
\hline United States & $(n=86,105)$ & $(n=9,965,336)$ \\
\hline Home & 1,436 & $6,566,321$ \\
\hline $\begin{array}{l}\text { Skilled care/ } \\
\text { rehabilitation }\end{array}$ & 11,854 & $2,489,062$ \\
\hline Dead & 264 & 595,109 \\
\hline Short term hospital & 5,870 & 279,631 \\
\hline LTAC & 66,562 & 25,110 \\
\hline Unknown & 119 & 10,103 \\
\hline United States, ICU only & $(n=40,600)$ & $(n=1,699,545)$ \\
\hline Home & 450 & 955,182 \\
\hline $\begin{array}{l}\text { Skilled care/ } \\
\text { rehabilitation }\end{array}$ & 5,439 & 397,987 \\
\hline Dead & 55 & 253,580 \\
\hline Short term hospital & 3,108 & 83,476 \\
\hline LTAC & 31,528 & 7,652 \\
\hline Unknown & 20 & 1,668 \\
\hline $\begin{array}{l}\text { United States, ventilated } \\
\text { only }\end{array}$ & $(n=19,938)$ & $(n=221,188)$ \\
\hline Home & 104 & 47.661 \\
\hline $\begin{array}{l}\text { Skilled care/ } \\
\text { rehabilitation }\end{array}$ & 2,582 & 54,270 \\
\hline Dead & 8 & 105,320 \\
\hline Short term hospital & 1,809 & 10,258 \\
\hline LTAC & 15,420 & 3,468 \\
\hline Unknown & 15 & 211 \\
\hline Pennsylvania & $(n=4,458)$ & $(n=490,899)$ \\
\hline Home & 65 & 313,799 \\
\hline $\begin{array}{l}\text { Skilled care/ } \\
\text { rehabilitation }\end{array}$ & 525 & 136,266 \\
\hline Dead & 1 & 26,707 \\
\hline Short term hospital & 338 & 12,259 \\
\hline LTAC & 3,495 & 1,366 \\
\hline Unknown & 34 & 502 \\
\hline Pennsylvania, ICU only & $(\mathrm{n}=2,107)$ & $(\mathrm{n}=80,052)$ \\
\hline Home & 21 & 41,724 \\
\hline $\begin{array}{l}\text { Skilled care/ } \\
\text { rehabilitation }\end{array}$ & 246 & 22,268 \\
\hline Dead & 0 & 11,820 \\
\hline Short term hospital & 149 & 3,745 \\
\hline LTAC & 1,690 & 432 \\
\hline Unknown & 1 & 63 \\
\hline $\begin{array}{l}\text { Pennsylvania, ventilated } \\
\text { only }\end{array}$ & $(n=1,216)$ & $(n=10,473)$ \\
\hline Home & 4 & 2,020 \\
\hline $\begin{array}{l}\text { Skilled care/ } \\
\text { rehabilitation }\end{array}$ & 140 & 2,909 \\
\hline
\end{tabular}

Table 1 Contents of the discharge destination field in Medicare categorized by actual transfer to a long-term acute care hospital (Continued)

\begin{tabular}{lcc}
\hline Dead & 0 & 4,863 \\
Short term hospital & 95 & 438 \\
LTAC & 976 & 232 \\
Unknown & 1 & 11 \\
\hline
\end{tabular}

ICU = intensive care unit; LTAC = long-term acute care hospital

patients transferred to long-term acute care hospitals. The specificity of the test was high, resulting in a relatively low false positive rate and high negative predictive value. However, the sensitivity was somewhat low, resulting in a high false negative rate and low positive predictive value. When false negatives occurred, the patients were most frequently classified as having been transferred to skilled nursing facilities, inpatient rehabilitation hospitals or acute care hospitals rather than LTACs. The performance characteristics of the discharge destination field were consistent across key subgroups of patients, indicating that coding error was not conditional on prevalence of LTAC utilization.

These results have important implications for LTACrelated research. Ideally, investigators using administrative data to study LTACs should only use data with direct patient identifiers that allow tracking of patients across hospitalizations. Unfortunately, due to privacy restrictions and other data constraints, few administrative hospital discharge data sets contain this information [5]. For example, US state discharge data sets like those available in the Agency for Healthcare Research and Quality's Healthcare Costs and Utilization Project do not have this capability. Researchers that must use unidentified hospitalization data to study LTACs should recognize the limitations of the discharge destination field for identifying LTAC transfers. Sensitivity analyses that account for false negatives and other classification errors are necessary to understand how such errors could potentially bias results. For investigations in which accurate identification of LTAC transfer is crucial, the limitations the discharge destination field in unidentified administrative data may preclude its use.

For research that uses the discharge location field to identify LTACs, the implications of misclassification will depend on how researchers use the field. Given the high positive predictive value, researchers that use LTAC transfer as an outcome (i.e. patient factors associated with transfer to an LTAC) can be reasonably certain that patients meeting the outcome are true positives. Assuming non-differential misclassification, the misclassification serves mainly to decrease power. However, if a researcher wishes to study the incidence or outcomes of patients transferred to LTACs, the high false negative 
Table 2 Performance characteristics of the discharge destination field for identifying patients transferred to a longterm acute care hospital after an acute care hospitalization

\begin{tabular}{|c|c|c|c|c|c|c|c|}
\hline & Transfer Prevalence, \% & $\begin{array}{c}\text { Sensitivity, \% } \\
(95 \% \mathrm{Cl})\end{array}$ & $\begin{array}{c}\text { Specificity, \% } \\
(95 \% \mathrm{Cl})\end{array}$ & $\begin{array}{l}\text { PPV, \% } \\
(95 \% \mathrm{CI})\end{array}$ & $\begin{array}{l}\text { NPV, \% } \\
(95 \% \mathrm{CI})\end{array}$ & $\begin{array}{c}+ \text { LR } \\
(95 \% \mathrm{Cl})\end{array}$ & $\begin{array}{c}- \text { LR } \\
(95 \% \mathrm{Cl})\end{array}$ \\
\hline United States & 0.8 & $\begin{array}{c}77.3 \\
(77.0-77.6)\end{array}$ & $\begin{array}{c}99.7 \\
(99.7-99.8)\end{array}$ & $\begin{array}{c}72.6 \\
(72.3-72.9)\end{array}$ & $\begin{array}{c}99.8 \\
(99.8-99.8)\end{array}$ & $\begin{array}{c}307 \\
(303-311)\end{array}$ & $\begin{array}{c}0.23 \\
(0.23-0.23)\end{array}$ \\
\hline United States, intensive care only & 2.3 & $\begin{array}{c}77.7 \\
(77.3-78.1)\end{array}$ & $\begin{array}{c}99.6 \\
(99.5-99.6)\end{array}$ & $\begin{array}{c}80.5 \\
(80.1-80.9)\end{array}$ & $\begin{array}{c}99.5 \\
(99.5-99.5)\end{array}$ & $\begin{array}{c}172 \\
(169-176)\end{array}$ & $\begin{array}{c}0.22 \\
(0.22-0.23)\end{array}$ \\
\hline United States, ventilated only & 8.3 & $\begin{array}{c}77.3 \\
(76.8-77.9)\end{array}$ & $\begin{array}{c}98.4 \\
(98.4-98.5)\end{array}$ & $\begin{array}{c}81.6 \\
(81.1-82.2)\end{array}$ & $\begin{array}{c}98.0 \\
(97.9-98.0)\end{array}$ & $\begin{array}{c}49.3 \\
(47.7-51.0)\end{array}$ & $\begin{array}{c}0.23 \\
(0.22-0.24)\end{array}$ \\
\hline Pennsylvania & 0.9 & $\begin{array}{c}78.4 \\
(77.2-79.6)\end{array}$ & $\begin{array}{c}99.7 \\
(99.7-99.7)\end{array}$ & $\begin{array}{c}71.9 \\
(70.6-73.2)\end{array}$ & $\begin{array}{c}99.8 \\
(99.8-99.8)\end{array}$ & $\begin{array}{c}28.9 \\
(27.3-30.5)\end{array}$ & $\begin{array}{c}0.22 \\
(0.21-0.24)\end{array}$ \\
\hline Pennsylvania, intensive care only & 2.6 & $\begin{array}{c}80.2 \\
(78.4-81.9)\end{array}$ & $\begin{array}{c}99.5 \\
(99.4-99.5)\end{array}$ & $\begin{array}{c}79.6 \\
(77.9-81.3)\end{array}$ & $\begin{array}{c}99.5 \\
(99.4-99.5)\end{array}$ & $\begin{array}{c}149 \\
(135-164)\end{array}$ & $\begin{array}{c}0.20 \\
(0.18-0.22)\end{array}$ \\
\hline Pennsylvania, ventilated only & 10.4 & $\begin{array}{c}80.3 \\
(77.9-82.5)\end{array}$ & $\begin{array}{c}97.8 \\
(97.5-98.1)\end{array}$ & $\begin{array}{c}80.8 \\
(78.5-83.0)\end{array}$ & $\begin{array}{c}97.7 \\
(97.4-98.0)\end{array}$ & $\begin{array}{c}36.2 \\
(31.8-41.3)\end{array}$ & $\begin{array}{c}0.20 \\
(0.18-0.23)\end{array}$ \\
\hline
\end{tabular}

$\mathrm{Cl}=$ confidence interval; $\mathrm{PPV}=$ positive predictive value; $\mathrm{NPV}=$ negative predictive value; $\mathrm{LR}=$ likelihood ratio. All values percents

rate would mean that a substantial number of patients would be missed. Researchers should exercise particular caution in this instance. In either case, the degree to which misclassification is differential (i.e. systematically conditional on hospital or patient level factors) will lead to potentially important bias. Future studies should examine whether misclassified patients differ in fundamental ways from correctly classified patients.

Our study has several limitations. We analyzed only one administrative data source. The performance characteristics of the discharge destination field may differ among different data sources. Nonetheless, given the historical importance of Medicare data for hospital reimbursement and health services research, we strongly doubt that they are systematically less accurate than other administrative data. We also used a potentially imperfect reference standard. Although our method should capture nearly all LTAC transfers, we could misclassify patients with incorrectly coded admission and discharge dates, or patients admitted to LTACs through means other than direct transfers, an extremely rare occurrence [10]. Additionally, we could not determine the true discharge destination of false positives (i.e. patients thought to have undergone LTAC discharge by the discharge destination field but who did not actually under LTAC transfer) or determine the patient-level factors associated with misclassification. Future research that fills these knowledge gaps may help researchers understand the implications of misclassification when using the discharge destination field, perhaps expanding the role of unidentified data in LTAC research. Finally, LTACs as a hospital type are specific to the United States; our findings are not applicable to other countries.

In conclusion, the discharge destination field in administrative data can result in misclassification of patients transferred to long-term acute care hospitals. Directly observing transfers in the claims is the preferable method, although this approach is only feasible in identified data.

\section{Funding}

Funded by R01 HL096651 from the United States National Institutes of Health (Kahn). Drs. Kahn and Iwashyna are supported by a career development awards from the United States National Institutes of Health (K23 HL096651, Kahn; K08 HL091249, Iwashyna). This study was also funded in part from a grant from the Pennsylvania Department of Health, which specifically disclaims responsibility for any analyses, interpretations or conclusions.

\section{Acknowledgements}

The authors gratefully acknowledge the expert programming of Maximillian Herlim.

\section{Author details}

${ }^{1}$ Center for Clinical Epidemiology \& Biostatistics, University of Pennsylvania School of Medicine, Blockley Hall 723, 423 Guardian Drive, Philadelphia, PA 19104. ${ }^{2}$ Division of Pulmonary \& Critical Care, University of Michigan, 3A23 300 NIB, SPC 5419, 300 North Ingalls, Ann Arbor, MI 48109.

\section{Authors' contributions}

JK designed the study, analyzed the data, interpreted the results and drafted the manuscript. Tl obtained the data, provided input into study design, interpreted the results and critically revised the manuscript for important content. All authors read and approved the final manuscript.

\section{Competing interests}

Dr. Kahn is employed by the University of Pennsylvania, which owns and operates a long-term acute care hospital under a cooperative agreement with Good Sheppard Rehabilitation Network-both are non-profit entities. Dr. Kahn also receives grant funding from the United States National Institutes of Health to study long-term acute care hospitals. Dr. Iwashyna reports no competing financial interests.

Received: 18 March 2010 Accepted: 21 July 2010

Published: 21 July 2010

\section{References}

1. Carson SS: Know your long-term care hospital. Chest 2007, 131:2-5. 
2. Scheinhorn DJ, Hassenpflug MS, Votto JJ, Chao DC, Epstein SK, Doig GS, Knight EB, Petrak RA: Ventilator-dependent survivors of catastrophic illness transferred to 23 long-term care hospitals for weaning from prolonged mechanical ventilation. Chest 2007, 131:76-84.

3. Kahn JM, Benson NM, Appleby D, Carson SS, Iwashyna TJ: Long-term acute care hospital utilization after critical illness. JAMA 2010, 303:2253-2259.

4. Kahn JM: The evolving role of dedicated weaning facilities in critical care. Intensive Care Med 2010, 36:8-10.

5. Wunsch $\mathrm{H}$, Harrison DA, Rowan $\mathrm{K}$ : Health services research in critical care using administrative data. J Crit Care 2005, 20:264-269.

6. Peabody JW, Luck J, Jain S, Bertenthal D, Glassman P: Assessing the accuracy of administrative data in health information systems. Med Care 2004, 42:1066-1072.

7. Iwashyna TJ, Christie JD, Moody J, Kahn JM, Asch DA: The structure of critical care transfer networks. Med Care 2009, 47:787-793.

8. Scales DC, Guan J, Martin CM, Redelmeier DA: Administrative data accurately identified intensive care unit admissions in Ontario. $J$ Clin Epidemiol 2006, 59:802-807.

9. Quan H, Parsons GA, Ghali WA: Validity of procedure codes in International Classification of Diseases, 9th revision, clinical modification administrative data. Med Care 2004, 42:801-809.

10. Liu K, Baseggio C, Wissoker D, Maxwell S, Haley J, Long S: Long-term care hospitals under Medicare: facility-level characteristics. Health Care Financ Rev 2001, 23:1-18.

doi:10.1186/1756-0500-3-205

Cite this article as: Kahn and Iwashyna: Accuracy of the discharge destination field in administrative data for identifying transfer to a long-term acute care hospital. BMC Research Notes 2010 3:205.

\section{Submit your next manuscript to BioMed Central and take full advantage of:}

- Convenient online submission

- Thorough peer review

- No space constraints or color figure charges

- Immediate publication on acceptance

- Inclusion in PubMed, CAS, Scopus and Google Scholar

- Research which is freely available for redistribution

Submit your manuscript at www.biomedcentral.com/submit
Biomed Central 